\title{
Performance ISSUES In ReCONFIGURABle MANUFACTURING SYSTEM
}

\author{
HASAN, F.; JAIN, P.K. \& KUMAR, D.
}

Abstract: Performance issues are very crucial for firms to understand the present state of the manufacturing system and to take suitable actions for maintaining firm's competitiveness. The generic functions of manufacturing performance measures helps to study the current state of manufacturing situation, monitor and control of operational efficiency, to drive the improvement program and to gauge the effectiveness of manufacturing decisions. Since, the modern manufacturing challenge is to have a responsive manufacturing system and Reconfigurable Manufacturing System is a step forward in this direction. This system is characterized as being responsive, whose production capacity and functionality can be adjusted as and when required. Since RMSs are still in a very nascent stage thus it becomes important to investigate and highlight some of the performance issues so that practical implementation of such system may get realized. The chapter presents some such issues and a comprehensive framework to assess the performance of such systems.

Key words: RMS, performance, reconfigurable machines, configuration
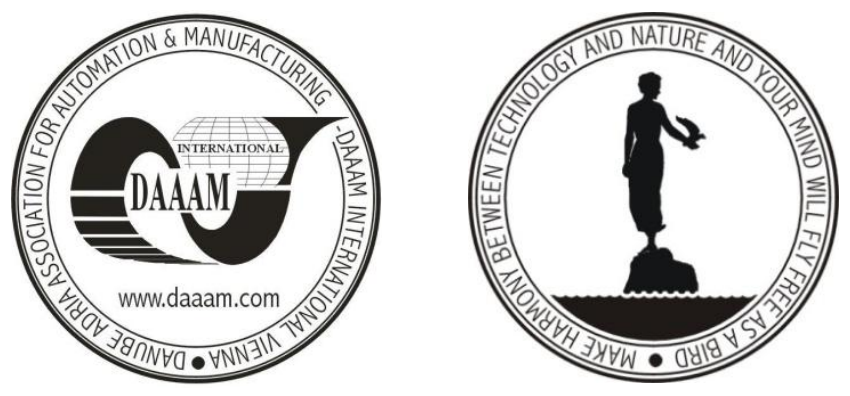

Authors' data: Research Scholar Hasan, F[aisal]; Prof. Jain, P[ramod] K[umar]; Prof. Dinesh, K[umar], Mechanical \& Industrial Engineering Department, Indian Institute of Technology Roorkee, India, faisalhasan123@rediffmail.com, pjainfme@iitr.ac.in, dinesfme@iitr.ac.in.

This Publication has to be referred as: Hasan, F[aisal]; Jain, P[ramod] K[umar] \& Dinesh, K[umar] (2014). Performance Issues in Reconfigurable Manufacturing System, Chapter 24 in DAAAM International Scientific Book 2014, pp.295-310, B. Katalinic (Ed.), Published by DAAAM International, ISBN 978-3-901509-98-8, ISSN 1726-9687, Vienna, Austria

DOI: $10.2507 /$ daaam.scibook.2014.24 
Hasan, F.; Jain, P. K. \& Dinesh, K.: Performance Issues in Reconfigurable Manufac...

\section{Introduction}

The present manufacturing era is characterized by high degree of customized products, lower product life cycle and high degree of cost reduction. The manufacturing firms now days required a prompt change or adjustment of the manufacturing facilities in wake of new customer needs and upcoming market demands. To have an edge over others, the manufacturing companies are continually striving to use such resources or facilities that not only produce their products with high productivity and lower cost but also provide them with some degree of flexibility to cope up with stochastic changes in market and customer perspectives. Earlier, the product life cycle is considered to be long with almost no change in the product design and the sole objective was focused towards high production volume at reduced costs. On the contrary, the modern manufacturing characteristics are based on effective and timely response of manufacturing systems to market scenario. In context of manufacturing systems, the term "response" or "responsiveness" is considered as an attribute which facilitates quick launch new products and to react quickly and cost-effectively to (1) market changes that includes changes in product demand, changes in existing product design; and introduction of new products (2) customer's orders (3) government regulations (safety and environment), and (4) system failures. These changes are driven by aggressive economic competition on global scale together clubbed with more educated and demanding customers, and a rapid pace of change in process technologies (Koren \& Ulsoy, 1997). In order to survive in this new manufacturing environment, companies must be adequately equipped to react to changes rapidly and cost effectively.

A Reconfigurable Manufacturing System (RMS) is considered to be a responsive system whose production capacity is adjustable to market fluctuations and whose functionality is adaptable to a variety of new products. The design of RMS evolves over a period of time in wake of customer needs and market demands. In today's manufacturing world, RMS is being recognized as a system for increasing productivity and profits despite of abrupt fluctuations pertaining to product volume and design and the process technologies. To some extent, the shop floor implementation of this newer class of manufacturing system becomes possible with the invention of Reconfigurable Machines (RMs). These machines are the basic building block RMSs, as several operations can be performed on these reconfigurable machines in its existing configuration and the operational functionality and capacity can be further altered by manipulating the modular structure of these machines in an intelligent way. Apart from high costs there are several other issues mostly related with the design, operation and performance evaluation which have gained wider significance in view of physical implementation of RMSs on the shop floor. Efforts are still required to take up issues related to RMSs so that they can be economically and successfully implemented and subsequently one can achieve the long term advantages associated with these systems. The present chapter presents a review of 
work carried out on performance measure and finally a holistic framework is proposed for performance aspect for RMS.

\section{The Need for RMS}

The present manufacturing arena is characterized by strong competition among stakeholders; this includes implementation of state of art technologies in product design and development, high degree of customized products, very strong supplychain relationships, abrupt fluctuations in product design and demand, shorter lead times and rapid introduction of new products and that too at reduced costs. Also, some very frequent governmental regulations mostly based on environment and climate may also lead to alteration, redesign and reconfiguration of manufacturing systems. In order to survive within such dynamic, constrained and highly demanding global manufacturing environment, the manufacturing enterprises are forced to opt for such manufacturing systems which are responsive to these above listed factors. Precisely, the newer manufacturing systems must be able to adjust to fluctuations in product demand and the functionality of which is adaptable not only to changes within the existing product's design but for new products as well.

The solution to all the modern manufacturing requirements was suggested by Koren et al. (1999) in the form of RMS. This newer class of manufacturing system is having combined advantages which were individually associated with DMS and FMS on capacity-functionality basis (Figure-1). The RMS is designed at the outset to offer the exact functionality and capacity, exactly when it is needed.

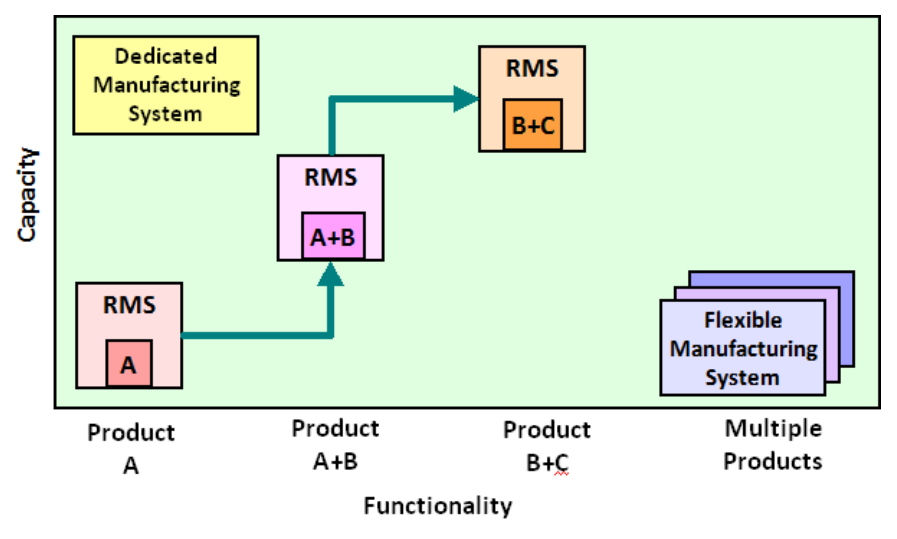

Fig. 1. Evolution of RMS with product functionality and demand and its comparison with DMS and FMS on functionality-capacity coordinate

\section{Introduction to RMS}

RMS is characterized as the one having the capability to respond to unpredictable market changes in a cost effective manner by manipulation of its capacity and functionality with the objective of enhancing manufacturing responsiveness. The importance of reconfigurable manufacturing can be recognized 
Hasan, F.; Jain, P. K. \& Dinesh, K.: Performance Issues in Reconfigurable Manufac...

by the fact that this novel concept has been identified as the leading priority for future manufacturing, and is among one of the six key research challenges identified by National Research Council (NRC, 1998), USA.

Initial idea for RMS was proposed by Liles and Huff (1990) as the system capable of intelligently utilizing the configuration of manufacturing system to fulfil the dynamic production demand. Later, Tsukune et al. (1993) gave the concept of 'modular manufacturing' which is very much similar to RMS. Breakthrough in the field of RMS came in the year 1996 when the Engineering Research Centre for Reconfigurable Manufacturing Systems (ERC/RMS) was established at the University of Michigan, Ann Arbor, USA to design, develop and implement RMSs. Koren et al. (1999) defined RMS as "A Reconfigurable Manufacturing System (RMS) is a system designed at the outset for rapid change in structure, as well as in hardware and software components, in order to quickly adjust production capacity and functionality within a part family". The up-gradation or modification of RMS is carried out through the process of reconfiguration in its structure both at hardware and software level. The systematic development and up-gradation of RMS through reconfiguration process is presented in Figure 2.

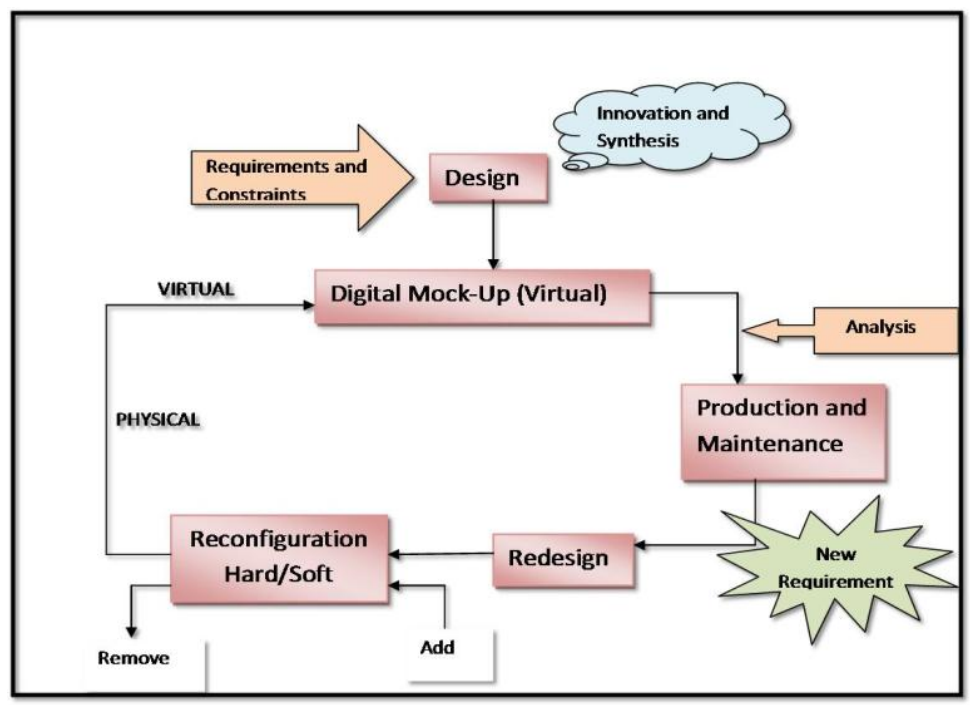

Fig. 2. Schematic development and execution of RMS

Reconfigurability of system can be attained if the design of these systems is based on several key core characteristics of modularity, integrability, customization, scalability, convertibility, and diagnosibility. The six key RMS characteristics governs the ease and cost of reconfigurability of manufacturing systems, and thereby enable rapid responsiveness of the system or an enterprise as a whole to sudden market changes (Koren, 2013). Upon analysing the relationship between the RMS core characteristics and the RMS definition, it can be said that, the characteristics of customization, scalability and convertibility are essential for a system to be reconfigurable in nature. While on the other side, the other three characteristics of 
modularity, integrability and diagnosability are supporting characteristics that make the RMS conversions efficient in terms of reconfiguration time and effort.

\section{Performance Issues}

Performance issues and their measures are crucial for firms not only to understand the present system state but to take measures for maintaining firm's competitiveness. Though, some performance measures were developed and were reported in literature, these measures include both practical and theoretical ones. However, the selection of any measure must have reasonable rationale behind its selection and it should account for the desired manufacturing objective. Though, the classical goal of manufacturing which aims to produce the required quantity at the required time by the best and economical method still remains valid today but such a generic aim needs further improvements in context of system's responsiveness. Generally, manufacturing systems typically composed of group of machines/stations or stages arranged in some specific manner to suit operational precedencies. These individual machines/stations may have distinct performance levels in terms of production rate, cost, reliability, availability, capacity and functionality which in turn determine the overall performance of the manufacturing system.

The literature reviewed on performance issues concerning RMS showed that cost is one of the most discussed issue for manufacturing system's design and operation and which in turns reflects the performance. Some other performance parameters found in literature include throughput, ramp-up time, availability and reliability. For RMS performance issues, the focussed parameters must productivity or production rate, resource utilization, reliability and availability considerations, scalability and part family formation techniques. These issues can be related to either design or operations of such systems. Some of the pertinent performance issues which were taken up in past are summarized as under.

\subsection{Cost}

According to Hon (2005) cost is of utmost concern for evaluation of performance of manufacturing system though its degree of comprehensiveness is very low. One of the initial efforts to capture reconfiguration costs in RMS was carried out by Son et al. (2001) who proposed a similarity based reconfiguration RMS models. Later, Youssef and ElMaraghy (2005) presented a related reconfiguration cost model for assessing reconfiguration smoothness. Deif and ElMaraghy (2006a) proposed a cost model which combines both the physical capacity cost based on capacity size and costs associated with the reconfiguration path comprised of both penalty and effort cost related to scalability. Spicer and Carlo (2007) studied the cost as a performance indicator while deciding upon the optimal configuration path of a scalable RMS that minimizes investment and reconfiguration costs over predetermined time horizon under known demand condition. The cost model given by Spicer and Carlo (2007) comprehends labour costs, lost capacity costs, and investment/salvage costs due to system reconfiguration and ramp up. In line with the findings of Kuzgunkaya and ElMaraghy (2009) it may be concluded for 
any manufacturing system and in particular RMS, the performance model may be evaluated by taking into account the operational costs, reconfiguration costs and effective utilization of machines while minimizing the system complexity and maximizing its responsiveness.

\subsection{Throughput}

Throughput refers to the number of units or parts that leaves the manufacturing system upon completion of all the desired operations over some specified period of time. The performance of manufacturing system may be evaluated either taking throughput alone as an objective or it may be used in combination with other performance variables like cost, quality and reliability etc. as a multi objective performance evaluation problem.

Musharavati (2011) formulated an objective function for performance based on throughput and cost. The objective was to carry out optimal configuration selection for RMS which minimizes the implicit function expressed as a ratio of cost to throughput. Tang et al. (2004) introduced an approach for designing multi part reconfigurable product line based on the minimal ratio of cost to throughput as the criterion for the fitness evaluation while deciding upon the configuration and task allocations. Tang et al. (2005) further used the same objective function of cost to throughput ratio to prove that, for the same number of machines, the multiple parts reconfigurable manufacturing system (MPRMS) comes out to be more efficient and economical than the traditional single-part manufacturing system. The evaluation criterion used by Ismail et al. (2008) was also based on a mathematical function formulation that combines processing costs and throughput for process planning optimization in reconfigurable multi parts product flow lines. Throughput model using probabilistic system states for RMS was proposed by Hasan et al. (2012). The RMS throughput is significantly affected by several factors such as, reconfiguration ramp-up time, the reliability of a single component or equipment and process; and the buffer allocations. Throughput model based on these parameters was formulated by Chao et al. (2007) for performance evaluation of manufacturing systems with reconfigurable configurations. Production rate in terms of low throughput time values was also used as a performance measure for studying different scheduling rules for manufacturing systems (Goyal et al., 1995). According to Zhang and Rodrigues (2009), the selection of RMS configuration should contribute to the improvement of certain system performance attributes which must include throughput, machine utilization and quality. The throughput parameter holds an inverse relationship with cycle time i.e. the smaller the cycle time, the greater the throughput. If cycle time is selected as the system performance indicator which is to be optimized then the optimal configuration can be defined as the one under which the reconfigurable flow shop functions with the minimal cycle time (Ren et al., 2007). Youssef and ElMaraghy (2006a) suggested that models developed for the design and development of RMSs must accommodate the throughput parameter to evaluate the various economical configurations being produced upon changes in the customer needs or requirements. 
In a nutshell, it can be concluded that an optimal manufacturing strategy or the plan is one that gives desired throughput with minimum processing cost under dynamic changes in production scenarios and is bound to result in optimal operating levels of modern manufacturing systems.

\subsection{Reliability and Availability}

The reliability of the system is defined as the probability that a system performs without failure up to some specified period of time. The contribution of reliability of a station to a multi station system is dependent on the configuration. Therefore, reliability analysis is considered to be an important performance issue and an essential part of configuration design. Determining the reliability of any complex systems like that of a manufacturing system is not an easy task because of large number of interlinked components within it. The approaches generally applied for system reliability modelling and estimation are based on either simple part count, combinatorial approaches such as Reliability Block Diagrams (RBD) and Fault Tree Analysis (FTA) and state space Markov analysis. Alternatively, availability is also defined as the probability indicating a system is operational at a given time, i.e. the amount of time a system is actually operating as the percentage of the expected total time it should be operating. In some situations, improved availability feature may allow the system to remain stay operational even when some faults occur.

Reliability and availability can be taken as important parameters which the newer manufacturing systems must inherit so that the degree of responsiveness may be improved upon. The impact of manufacturing system configuration on reliability and availability has been taken up in the past. The parameters of reliability and availability require due attention while carrying out reconfiguration planning for design and operation of modern system like RMSs. Nourelfath et al. (2003) even defined a reconfigurable manufacturing system as "the one which may allow service continuity under failure, on the basis of reduced level of functionality" meaning thereby that upon failure of any component the rest of the system keeps working but with some acceptable performance degradation. Reconfiguration modelling on the basis of reliability and availability was carried out by Norelfath et al. (2003). Availability and reliability considerations were taken by Dhouib et al. (2010) to calculate the throughput variances for transfer product lines composed of several machines with distinct reliability and maintainability characteristics.

Yang and $\mathrm{Hu}$ (2000) studied the effect of configuration design (parallel, series, and mixed) on the system performance using machine level reliability models. Youssef and ElMaraghy (2008a) presented a comprehensive study on how reliability and availability can be considered for multiple-aspect RMS configurations problems. Nevertheless, the literature reviewed on reliability and availability of RMS revealed that research works which takes into account the multiple aspects of RMS problems, either narrow down the problem to a single part family (Son et al., 2001) or certain assumptions were made to simplify the problem at the expense of reliability and quality (Tang et al., 2004) and in many researches on RMS planning and selection, the availability or reliability factor has not been considered at all (Youssef \& ElMaraghy 2006b). 


\subsection{Scalability}

In RMS, scalability is defined as the system's adaptability to changes in production capacity through its reconfiguration. The concept of scalability in RMSs came into existence when reconfigurable machines were invented. Such machines have modular structure that can be quickly reconfigured to achieve increased capacity and adaptability to a variety of product designs. Spicer et al. (2005) introduced the basic idea of scalable machines by designing RMTs which provides the option of adding or removing spindles to manipulate the capacity.

Dynamic approach towards capacity scalability modelling based on feedback control for RMS was proposed by Asl and Ulsoy (2002a). Deif and ElMaraghy (2006b, 2007b) also developed a dynamic model for capacity scalability for RMS. Results of their findings highlighted the trade-off decisions between responsiveness and cost while designing the capacity scalability controllers for RMS. For RMS, station paralleling within a stage as one of the possible approach towards scalability was proposed by Son et al. (2001). The outcome of the study by Son et al. (2001) demonstrated that stage paralleling was a better alternative over line balancing for scalability. However, unbalancing as scalability approach was not considered by Son et al. (2001) in their study. Wiendahl and Breithaupt $(1999,2000)$ suggested a capacity scalability approach using flexibility curves, where these flexibility curves indicated the time delay of the controller unit for capacity scaling step, based on some predefined backlog value of work in process inventory. In a work by Deif and ElMaraghy (2006b) on scalability of RMS indicated that there exists a relationship between optimal capacity scalability planning horizon and reconfiguration costs. The results highlighted the fact that decreased costs of reconfiguration would lead to cost effective implementation of these systems. The most practical approaches are mostly based on resource duplication, which negates the philosophy of RMS.

\subsection{Ramp-up}

Koren et al. (1999) defined ramp up as "the time duration it takes for a newly introduced or just reconfigured production system to reach sustainable, long term levels of production, in terms of throughput and part quality, considering the impact of equipment and labour on productivity". Also, ramp up can be defined as "the period during which a manufacturing process makes the transition from zero to full scale production at targeted levels of cost and quality" (Clark \& Fujimoto, 1991).

The ability to minimize the ramp-up time for production especially when new customized variety in products are to be introduced has become a critical performance issue for many manufacturing companies. Furthermore, in today's scenario the product life cycle is short and product customization is on ascend, thus giving rise to more recurrent production ramp ups than ever before. Hence, this trend compels the manufacturers to bring about production ramp-ups both in a timely and cost efficient manner. As identified by Matta et al. (2007), the issue concerning ramp up is primarily related to (1) identification and analysis of the factors affecting the period of the ramp-up and its associated costs (2) techniques used for reducing the ramp up duration with no compromise on quality (3) procedure adapted for reassessing the system ramp-up during its reconfiguration. A know how of how 
ramp-up affects the system's performance would enable the designers to decide upon the reconfiguration policies best suited to their requirements.

The literature reviewed on ramp up issue showed that most works focus on analysis of precise industrial issues and collection of related research experience. Several studies have concluded that it is only experience; learning and knowledge creation that may handle the issues related to production ramp up (Hatch \& Macher, 2004). Among few pertinent works on the impact of ramp up on reconfiguration, Deif and ElMaraghy $(2006 \mathrm{a}, 2007 \mathrm{c})$ studied the impact the reconfiguration costs which included ramp up costs on the overall economy of RMSs. Thus, cost effective implementation of an RMS is highly dependent on decreasing the cost of reconfiguration of these systems which in turn reflects that the cost associated with ramp up accordingly be reduced. Some researchers are of the opinion that it is much more important to decide a suitable policy of when, how, and how much to reconfigure the production system, under unreliable market demand. Further, they argued that it is not always beneficial to opt for high degree of reconfiguration very often as it would not always have economic benefits on ramp up time and associated costs (Asl \& Ulsoy, 2002a, 2002b). It can be concluded that to have successful application of RMS, work must be done to develop strategies and techniques which would decrease this delay and improve the ramp up time of new configurations to improve system's performance (Dief \& ElMaraghy, 2006b).

\subsection{Part Family Formation}

Part family is defined as a group of assembled parts having similarities in geometry, manufacturing process and/or functions. Part family formation is based on Group Technology (GT) philosophy which states that many problems are similar and by grouping similar problems, a single solution can be found to a set of problems, thus saving substantial time and effort.

The design of RMS revolves around a part family so as to accommodate the distinct geometrical and manufacturing features of that part family. The key attribute of product families is the fact that all the components within a family may require similar set of production resources. The major advantage of grouping part into families is that, if a manufacturing system is capable of producing a part within a family, then fundamentally it can produce all the part of that family. Since, RMSs have the capacity and functionality required to produce a complete product family, thus it may serve a cost effective answer to manufacturer requirements as per customer needs. As per definition, RMS design starts with the formation of part families and there after the configuration of RMS develops in response to changes in the product functionality and capacity. Differing to this, Xiaobo et al. (2000a, 2000b) defined and study an RMS which cater multiple part families. At the outset the RMS is built around a part family and subsequently in accordance with the upcoming new part families the existing system is reconfigured to suit the new requirements. On the basis of part family, Koren et al. (1999) also defined RMS as a system designed to furnish for the needs of a part family by reconfiguring its hardware and software components rapidly in response to the sudden market changes. The past works on 
part family formation addresses the philosophy or technique used for grouping of products into part families for which an RMS is to be designed.

In the work by Abdi and Labib (2004) on part family formation for RMS it has been stated that no research work was carried out prior to theirs on part grouping for RMS. Among conventional techniques clustering approach was commonly employed for grouping of parts based on similarity and dissimilarity measure for machines or parts. The major drawback of conventional grouping method was that it requires prior specification of machines, parts, and the total number of manufacturing cells. According to Abdi and Labib (2004) grouping part in RMS has a positive impact on its operation and it also facilitates the introduction of new product. The initial work on part family formation for RMS was carried out by Abdi and Labib (2004) in which parts were grouped into families based on Jacard's similarity coefficient. Formation of cell for RMS in the presence of reconfigurable machines was carried out by Pattanaik et al. (2007) based on minimization of intercellular movement. Another commonly employed algorithm for part family formation is Average Linkage Clustering (ALC), the viewpoint behind this algorithm is that the parts can be grouped together on the basis of similarities in their attributes. Rakesh et al. (2010) used hierarchical clustering algorithm based on operation sequence similarity to form sets of part families at different similarity levels and the corresponding operation groups for RMS.

In another work, Galan et al. (2007) developed a methodology for part family formation in RMS on part-pair similarity matrix. Afterward, Average Linkage Clustering (ALC) algorithm was applied to obtain a dendogram which depicts the diverse set of part families were formed for the considered numerical example. Till recently, Goyal et al. (2013) proposed, developed and demonstrated a novel part family formation methodology based on operation sequences in RMS. The developed methodology was based on similarity coefficient calculated using minimum bypass moves and minimum idle machines for any longest common subsequence (LCS) between parts.

To summarize, it can be concluded that grouping products into part families is an important issue for designing RMS for improved performance. Product grouping or part family formation allows the manufacturing system to cope with a wider range of customer requirements and to increase the utilization of manufacturing resources.

\subsection{Optimal Configuration Selection}

As mentioned earlier, the distinctive feature of an RMS is its capability to change configurations in a cost-effective manner in order to provide precise functionality and capacity needed for any demand period. These configuration changes can be carried out at two levels in an RMS environment (1) system level in which machines can be either added or removed from the system or they may in the form of layout change (Youssef and ElMaraghy, 2008a; Wiendahl et al. 2007; Dou et al. 2009b) (2) at machine level in the form of adding or removing axes, spindles or any other auxiliary module from machine tools i.e. changing configuration of machine tools, i.e., (Tang et al. 2005). The Reconfigurable Machines (RMs) facilitates the machine level reconfiguration (Koren and Kota, 1999; Koren et al. 
1999). However, RMTs recognized as indispensable enablers of RMS are not yet generally used in manufacturing systems (Wiendahl et al. 2007) but they certainly increases the likelihood of a system to be more reconfigurable. In a real world manufacturing scenario, considering the nonexistence of RMTs, most of the configuration selection problems focuses on system level reconfiguration of RMS rather than machine level reconfigurations i.e. it does not deal with how to reconfigure RMTs. Because of flexible structure of RMTs, there are usually several machine alternatives for each operation, thus the optimal selection of machines configuration must be dealt as it may have serious implication on cost and performance of the system.

In literature, the research works on the configuration selection problem for RMS are relatively few. One of the very early studies by Son et al. (2001) was perhaps the first which focused on configuration generation and selection problem for RMS. The problem was based on optimal configuration selection for single product reconfigurable flow line solved using genetic algorithm (GA) for generating alternative configuration. The configuration selection problem for single part flow line is to determine the number of stages, the number of paralleling machines and their types and the assignment of operations to each stage while the constraints are operations precedence, space, capacity and cost (Dou et al., 2009b). Xiaobo et al. (2000a) presented a comprehensive framework for optimal configuration selection problem in RMS. Based on the framework the author's proposed three important issues for configuration selection problem. These issues are (1) the optimal configurations in the design stage (Xiaobo et al. 2000b), (2) the optimal selection policy in the utilization stage (Xiaobo et al. 2001a) and (3) the performance measure in the improvement stage of these systems (Xiaobo et al. 2001b).

Koren et al. (1998) demonstrated that the system configuration selection has serious implications on six key performance measures, which are: throughput, capacity scalability, system conversion time, investment cost of machines and tools, number of product mix and quality. Maier-Speredelozzi and Hu (2002) worked on manufacturing system configuration selection by considering multiple performance criteria using AHP approach. Youssef and ElMaraghy (2006a) presented a GA based approach for optimal configuration selection in RMS. The objective function used for selection was based on minimizing the capital cost of multi-part flow line configurations. Also, Tang et al. (2005) developed a GA based approach to obtain the near optimal configuration for multi-product flow line. Pioneering work was carried out by Youssef and ElMaraghy (2007) towards optimal configuration selection problem for RMS. They suggested a two tier approach for this problem. The first phase deals in deciding upon a suitable configuration for upcoming demand period, in this a predefined number of feasible configuration alternatives were generated for the considered demand period. Subsequently in the second phase the objective was to select one feasible configuration from among the generated ones on the basis of reconfiguration smoothness. The reason for generating a good number of alternatives in the first phase was to offer the selection procedure adapted for the second phase with a diverse set of good feasible alternative configurations to choose from so that the best level of reconfiguration smoothness can be achieved. Youssef and ElMaraghy (2007) demonstrated the proposed approach by designing a multi-part reconfigurable flow line. 


\section{Proposed Framework}

Though plenty of literature exists on the issues concerning RMS but the wide review of the literature revealed that still there is wide scope of study in almost all the areas of RMS. The literature reviewed gives an overview regarding the present and future arena of research on RMS. There is a serious need to address the performance issues and develop more insight into some more practical aspects of these systems. To have real shop floor implementation of RMS, there is a serious need to develop cost effective reconfigurable machines which will definitely help in designing and implementing a system offering rapid and economic reconfigurations.

A holistic approach is required for RMS design and operation while optimizing multiple performance measures. The concern issues discussed are very important so as to convince the industrialists to design and adopt the facilitating technologies of reconfigurable manufacturing system. A comprehensive framework concerning RMS design and operation while optimizing the multiple performance parameters is presented in Figure 3.

As identified the design of any RMS should be based on the key enablers which includes all the six core characteristics which differentiate an RMS from their counter parts. Among these core enables, the modularity aspect is primarily concern to reconfigurable machines which should be designed with modular structure which facilities in achieving multiple functionality as well. In other words, convertibility feature may be introduced with ease for modular structure of these machines.

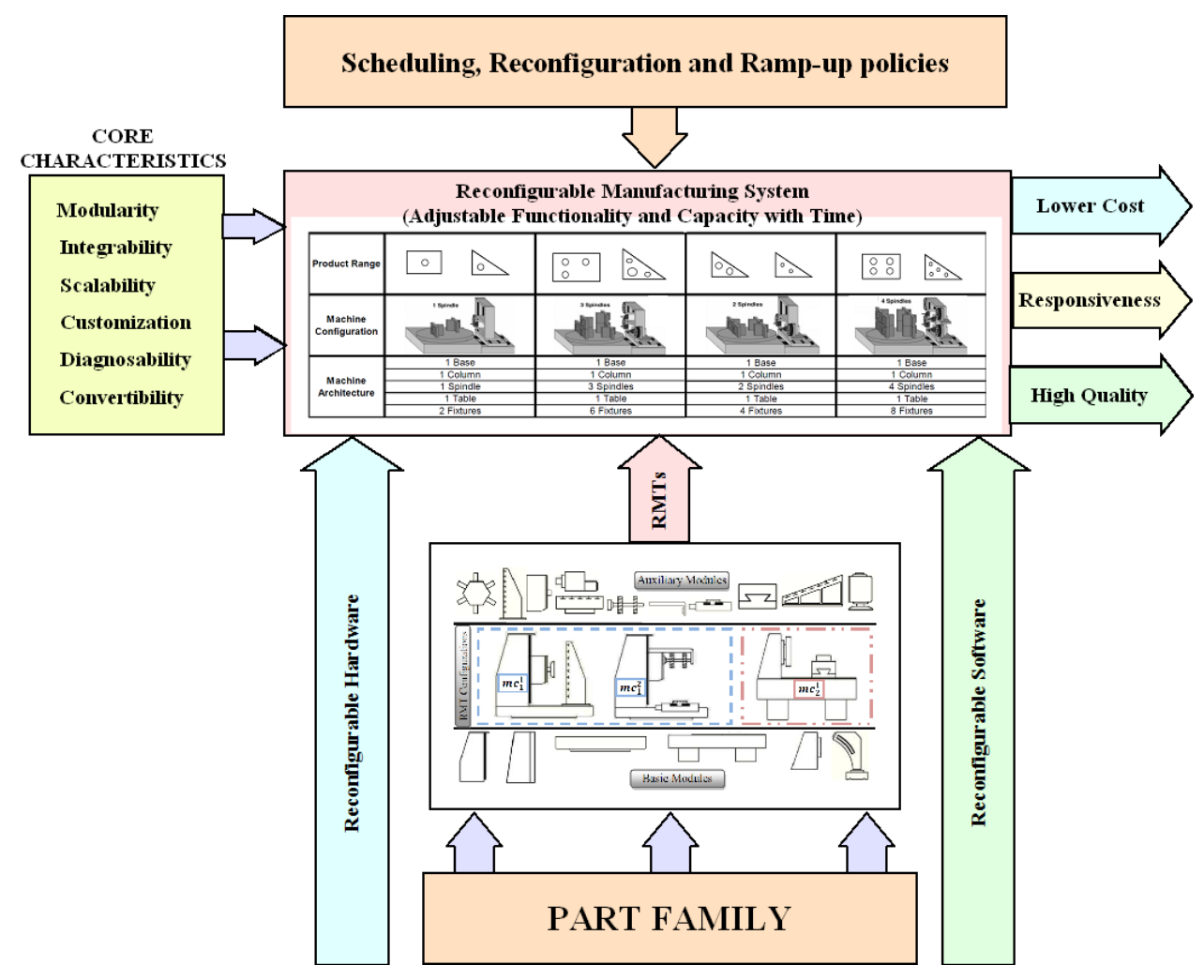

Fig. 3. A schematic overview of issues pertaining to RMS design, operation and performance measures 
Scalability issues might incorporate strategies like unbalancing which would also improve the throughput from such systems. One of the initial works concerning quantification of machine reconfigurability was proposed by Goyal et al. (2011) and much more is still required to address reconfigurability quantification in terms of multiple machine attributes.

The central theme of any RMS design revolves around the part family, thus, there is a need to develop strategies based on artificial intelligent and machine vision to facilitate the process of part family formation.

The major concern which has not been yet reported in literature is the scheduling and reconfiguration policies which are to be adapted to reduce the cost and take advantages with a system which is said to be reconfigurable, the outcome of which would be reflected in terms of lower costs, higher responsiveness and good quality products.

\section{References}

Abdi, M.R. \& Labib, A.W. (2004). Grouping and selecting products: the design key of Reconfigurable Manufacturing Systems (RMSs). International Journal of Production Research, Vol. 42, No. 3, pp.521-546

Asl, F.M. \& Ulsoy, A.G. (2002a). Capacity management in reconfigurable manufacturing systems with stochastic market demand. Proceedings of the 2002 ASME International Mechanical Engineering Congress and Exposition, New Orleans, Louisiana, USA

Asl, F.M. \& Ulsoy, A.G. (2002b). Capacity management via feedback control in reconfigurable manufacturing systems with stochastic market demand. Proceedings of the Japan-USA Symposium on Flexible Automation, Hiroshima, Japan

Chao, L.; Aping, L. \& Xu, L. (2007). The research of performance evaluation system on manufacturing system with reconfigurable configuration. Proceedings of the 2007 IEEE International Conference on Mechatronics and Automation, Harbin, China, pp. $1005-1010$

Clark, K.B \& Fujimoto, T. (1991). Product development performance: strategy, organization and management in the world auto industry. Harvard Business School Press

Deif, A. \& ElMaraghy, W. (2007b). Integrating static and dynamic analysis in studying capacity scalability in RMS. International Journal of Manufacturing Research, Vol. 2, No. 4, pp. 414-427

Deif, A.M. \& ElMaraghy, W. (2006a). Effect of reconfiguration costs on planning for capacity scalability in reconfigurable manufacturing systems. International Journal of Flexible Manufacturing Systems, Vol. 18, No. 3, pp. 225-238

Deif, A.M. \& ElMaraghy, W. (2006b). A control approach to explore the dynamics of capacity scalability in reconfigurable manufacturing systems. Journal of Manufacturing Systems, Vol. 25(1), pp. 12-24

Deif, A.M. \& ElMaraghy, W. (2007c) Investigating optimal capacity scalability scheduling in a reconfigurable manufacturing system. International Journal of Advance Manufacturing Technology, Vol. 32, pp. 557-562 
Hasan, F.; Jain, P. K. \& Dinesh, K.: Performance Issues in Reconfigurable Manufac...

Dhouib, K.; Ait-kadi, D. \& Bouti, A. (1993). Contribution to availability assessment of flexible manufacturing cells. Proceedings of $2^{\text {nd }}$ International conference and exhibition on Computer Integrated Manufacturing, Singapore, pp. 347-354

Dou, J.P.; Dai, X.Z. \& Meng, Z.D. (2009b). Graph theory-based approach to optimize single-product flow-line configurations of RMS. The International Journal of Advanced Manufacturing Technology, Vol. 41, No. 9, pp. 916-931

Galan, R.; Racero, J.; Eguia, I. \& Garcia, J. (2007). A systematic approach for product families formation in reconfigurable manufacturing systems. Robotics and Computer-Integrated Manufacturing, Vol. 23,Vol. 5, pp. 489-502

Goyal, K.K; Jain, P.K. \& Jain, M. (2011). A novel approach to measure machine reconfigurability in Reconfigurable Manufacturing System. Annals of DAAAM for 2011 \& Proceedings of the 22nd International DAAAM Symposium, Volume 22, No. 1, ISSN 1726-9679, ISBN 978-3-901509-83-4, Editor B. Katalinic, Published by DAAAM International, Vienna, Austria

Goyal, K.K; Jain, P.K. \& Jain, M. (2013). A comprehensive approach to operation sequence similarity based part family formation in the reconfigurable manufacturing system. International Journal of Production Research, Vol. 51, No. 6, pp. 1762-1776 Goyal, S.K.; Mehta, K.; Kodali, R. \& Deshmukh, S.G. (1995). Simulation for analysis of scheduling rules for a flexible manufacturing system. Integrated Manufacturing Systems, Vol. 6, No. 5, pp. 21-26

Hasan, F.; Jain, P. K. \& Dinesh, K. (2012). Throughput Model for Coupled Reconfigurable Product Line, Chapter 09 in DAAAM International Scientific Book 2012, pp. 095-106, B. Katalinic (Ed.), Published by DAAAM International, ISBN 978-3-901509-86-5,ISSN 1726-9687, Vienna, Austria

Hatch, N.W. \& Macher, J.T. (2004). Knowledge management in developing new technologies: mitigating the trade-off between time-to-market and manufacturing performance. Proceedings of the $2^{\text {nd }}$ World Conference on Production and Operations Management. Cancun

Hon, K.K.B. (2005) Performance and evaluation of manufacturing systems. CIRP Annals-Manufacturing Technology, Vol. 54, No. 2, pp. 139-154

Ismail, N.; Musharavati, F.; Hamouda, A. \& Ramli, A.R. (2008). Manufacturing process planning optimization in reconfigurable multiple parts flow lines. Journal of Achievements in Materials and Manufacturing Engineering, Vol. 31, No. 2, pp. 671677

Koren, Y. (2013). The rapid responsiveness of RMS. International Journal of Production Research, Vol. 51, No. 23-24, pp. 6817-6827

Koren, Y. \& Kota, S. (1999). Reconfigurable Machine Tools. US patent No. $5,943,750$, USA

Koren, Y. \& Ulsoy, A.G. (1997). Reconfigurable Manufacturing Systems, Technical report, ERC/RMS-TR-001-1997, University of Michigan, Ann Arbor

Koren, Y.; Hu, S.J. \& Weber, T.W. (1998) Impact of manufacturing system configuration on performance. Manufacturing Systems, Vol. 47, No. 1, pp. 2-5

Koren, Y.; Jovane, F.; Heisel, U.; Pritschow, G.; Ulsoy, A.G. \& Van Brussel, H. (1999) Reconfigurable manufacturing systems. Annals of the CIRP, Vol. 48, No. 2, pp. $527-540$ 
Kuzgunkaya, O. \& ElMaraghy, H.A. (2009). Economic and strategic justification of changeable, reconfigurable and flexible manufacturing. Chapter 17, ElMaraghy, H.A. (ed.), Changeable and Reconfigurable Manufacturing Systems, Springer, pp. 303-320 Liles, D.H. \& Huff, B.L. (1990) A computer based production scheduling architecture suitable for driving a reconfigurable manufacturing system. Computers and Industrial Engineering, Vol. 19, No. 1-4, pp. 1-5

Maier-Speredelozzi, V. \& Hu, S.J. (2002). Selecting manufacturing system configurations based on performance using AHP. Technical paper. Society of Manufacturing Engineers, MS No. 02-179, pp. 1-8

Matta, A.; Tomasella, M. \& Valente, A. (2007). Impact of ramp-up on the optimal capacity-related reconfiguration policy. International Journal of Flexible Manufacturing Systems, Vol. 19, No. 3, pp.173-194

Musharavati, F. (2011). A method for optimizing the reconfiguration design task in manufacturing systems. Proceedings of the 2011 International Conference on Industrial Engineering and Operations Management, Kuala Lumpur, Malaysia

National Research Council (NRC) (1998). Visionary Manufacturing Challenges for the year 2020, National Academy Press, USA

Nourelfath, M.; Ait-kadi, D. \& Soro, W.I., (2003). Availability modeling and optimization of reconfigurable manufacturing systems. Journal of Quality in Maintenance Engineering, Vol. 9, No. 3, pp. 284-302

Pattanaik, L.N.; Jain, P.K. \& Mehta, N.K. (2007). Cell formation in the presence of reconfigurable machines. International Journal of Advanced Manufacturing Technology, Vol. 34, pp. 335-345

Rakesh, K.; Jain, P.K. \& Mehta, N.K. (2010). A Framework for simultaneous recognition of part families and operation groups for driving a reconfigurable manufacturing system. Advances in Production Engineering and Management, Vol. 5, No. 1 , pp. 45-58

Ren, S.C.; Xu, D.; Wang, F. \& Tan, M. (2007). Timed event graph-based cyclic reconfigurable flow shop modeling and optimization. International Journal of Production Research, Vol. 45, No. 1, pp. 143-156

Son, S.Y.; Olsen, T.L. \& Yip-Hoi, D.M. (2001). An approach to scalability and line balancing for reconfigurable manufacturing systems. Integrated Manufacturing Systems, Vol. 12, No. 7, pp. 500-511

Spicer, P. \& Carlo, H.J. (2007). Integrating Reconfiguration Cost into the Design of Multi-Period Scalable Reconfigurable Manufacturing Systems. Journal of Manufacturing Science and Engineering, Vol. 129, No. 1, pp. 202-210

Spicer, P.; Koren, Y. \& Yip-Hoi, D.M. (2005). Scalable reconfigurable equipment design principles. International Journal of Production Research, Vol. 43, No. 22, pp. 4839-4852

Tang, L.; Yip-Hoi, D.M.; Wang, W. \& Koren, Y. (2004). Concurrent line-balancing, equipment selection and throughput analysis for multi-part optimal line design. International Journal of Manufacturing Science and Production, Vol. 6, No. 1-2, pp. $71-81$

Tang, L.; Yip-Hoi, D.M.; Wang, W. \& Koren, Y. (2005). Selection principles on manufacturing system for part family. In: Proceedings of the CIRP $3^{\text {rd }}$ International Conference on Reconfigurable Manufacturing 
Hasan, F.; Jain, P. K. \& Dinesh, K.: Performance Issues in Reconfigurable Manufac...

Tsukune, H.; Tsukamoto, M.; Matsushita, T.; Tomita, F.; Okada, K.; Ogasawara, T.; Takase, K. \& Tuba, T. (1993). Modular manufacturing. Journal of Intelligent Manufacturing, Vol. 4, pp. 163-181

Wiendahl, H.E. \& Breithaupt, J.W. (2000). Automatic production control applying control theory. International Journal of Production Economics, Vol. 63, No. 1, pp. 33-46

Wiendahl, H.P. \& Breithaupt, J.W. (1999). Modelling and controlling the dynamics of production systems. Journal of Production Planning \& Control, Vol. 10, No. 4, pp. 389-401

Wiendahl, H.P.; ElMaraghy, H.A.; Nyhuis, P.; Zah, M.F.; Wiendahl, H.H.; Duffie, N. $\&$ Brieke, M. (2007). Changeable manufacturing-classification, design and operation. Annals of the CIRP-Manufacturing Technology, Vol. 56, No. 2, pp. 783-809

Xiaobo, Z.; Jiancai, W. and Zhenbi, L. (2000a). A stochastic model of a reconfigurable manufacturing system-Part 1: A framework. International Journal of Production Research, Vol. 38, pp. 2273-2285

Xiaobo, Z.; Wang, J. \& Luo, Z. (2000b). A stochastic model of a reconfigurable manufacturing system-Part 2: Optimal configurations. International Journal of Production Research, Vol. 38, pp. 2829-2842

Xiaobo, Z.; Wang, J. \& Luo, Z. (2001a). A stochastic model of a reconfigurable manufacturing system-Part 3: Optimal selection policy. International Journal of Production Research, Vol. 39, pp. 747-758

Xiaobo, Z.; Wang, J. \& Luo, Z. (2001b). A stochastic model of a reconfigurable manufacturing system. Part 4: Performance measure. International Journal of Production Research, Vol. 39, pp. 1113-1126

Yang, S. \& Hu, S.J. (2000). Productivity analysis of a six CNC machine manufacturing system with different configurations. Proceedings of the 2000 Japan USA flexible automation conference, Michigan, pp. 499-505

Youssef, A.M.A. \& ElMaraghy, H.A. (2005). A New Approach for RMS Configuration Selection. Proceedings of CIRP $3^{\text {rd }}$ International Conference on Reconfigurable Manufacturing, University of Michigan, May 10-12, Ann Arbor, MI Youssef, A.M.A. \& ElMaraghy, H.A. (2006a). Modelling and optimization of multiple-aspect RMS configurations. International Journal of Production Research, Vol. 44, No. 22, pp. 4929-4958

Youssef, A.M.A. \& ElMaraghy, H.A. (2006b). Assessment of manufacturing systems reconfiguration smoothness. International Journal of Advance Manufacturing Technology, Vol. 30, No.1-2, pp. 174-193.

Youssef, A.M.A. \& ElMaraghy, H.A. (2007). Optimal configuration selection for reconfigurable manufacturing systems. International Journal of Flexible Manufacturing, Vol. 19, pp. 67-106

Youssef, A.M.A. \& ElMaraghy, H.A. (2008a). Availability consideration in the optimal selection of multiple-aspect RMS configurations. International Journal of Production Research, Vol. 46, No. 21, pp. 5849-5882

Zhang, L.L. \& Rodrigues, B. (2009). A petri-net based approach to reconfigurable manufacturing systems modeling. Journal of Systemics, Cybernetics and Informatics, Vol. 7, No. 1, pp. 18-24 